\title{
Determinants of Food Insecurity of Smallholder Farmers in Humbo Woreda
}

\author{
Ambachew Woreta Gemere \\ Department of Economics, Lecturer, Debark University \\ Debark, Ethiopia
}

\begin{abstract}
Food insecurity is a worldwide growing concern. According to the 2010 State of Food Insecurity report of the United Nation's Food and Agriculture Organization (UNFAO), nearly one billion people are estimated to be under- nourished, of which developing nations account for 98\% (UNFAO2010). Demeke et.al (1995) pointed out that, despite many efforts, food insecurity is still a prominent feature of Ethiopia. Half of the food insecure population of the Sub Saharan Africa is found in Ethiopia, which is one of the seven food insecure country in Sub Sahara Africa. The food insecurity situation in the Humbo woreda, Wolaita zone of Ethiopia shares similar features with that of the other regions (WVE, 2007). The problem of food insecurity has wide diversity and multiple dimensions, which ranges from the global to individual level. Nevertheless, variability, complexity and interrelated causes of household food insecurity and local responses during crisis require an analysis to move down to a household level. It is with regard to this that this study began with the primary objective of analyzing the determinants of household food insecurity of smallholder farmers in Humbo Woreda Southern Nation Nationality People Regional State. To achieve this objective, primary data were collected from a sample of farm households in the Woreda through a structured questionnaire. A total of 183 farm households' cases were included in the final analysis. In addition, secondary data were collected from different organizations and pertinent publications in order to elaborate the present situation of the food insecurity status in the study area. Logit model was used to identify and analyze the effect of explanatory variables on the dependent variable. A total of twelve explanatory variables were included in the regression. Out of these, six variables were found to be significant in terms of food insecurity. The variables that have a significant relationship with the probability of food insecurity are: Use of Chemical Fertilizer, Use of irrigation, Land Size, Livestock Size, Food Aid, and Farm Credit Use. The rest of the explanatory variables, namely age, sex, education level, family size, dependency ratio, and other sources of income, had no significant effect on the probability of food insecurity. Therefore, consideration of these factors is vital as it provides information that would enable one to undertake effective measures with the aim of improving food security status in the study area.
\end{abstract}

Keywords: Food insecurity, logit, Humbo woreda, smallholder farmers

DOI: $10.7176 / \mathrm{JPID} / 50-01$

Publication date:June $30^{\text {th }} 2019$

\section{Introduction}

Food insecurity is a worldwide growing concern.Accordingtothe2010State of Food Insecurity report of the United Nation's Food and Agriculture Organization(FAO), nearly one billion people are estimated to be undernourished,ofwhichdevelopingnationsaccountfor98\%(FAO2010). The International Red Cross is currently appealing for HKD 3.69 billion to support the humanitarian operations in 11 African countries, including Cameroon, Chad, Ethiopia, Kenya, Malawi, Namibia, Niger, Nigeria, Somalia, South Sudan and Zimbabwe. As of April 2017, over 5.1 million people affected by the food crisis have been reached (AFC, 2017).

Ethiopia is a land of contrast. With a population of over 80 million, Ethiopia is the second most populous country in Sub-Saharan Africa (UNFPA, 2011). The country has a long history, a mosaic of peoples and many diverse cultures. Ethiopia has good resource potential for development: agriculture, biodiversity, water resource, minerals, etc. Yet it is faced with advanced poverty that is broad, deep and structural. Ethiopia is one of the poorest countries in the world with worst scenario of poverty and food insecurity. Close to a quarter of the population in Ethiopia is malnourished with the largest proportion suffering from chronic hunger.

According to UNDP (2012), the average Gross National Income (GNI) per capital income is only US\$971, which is far below the average value of Sub-Saharan African countries of \$1966. The purchasing power of rural households remains weak, with nearly $40 \%$ of the rural population living in poverty and about $28 \%$ of the population living in extreme poverty with a financial gain of less than one greenback per capital per day.

MoFED (2013) reported that among the varieties of shocks Ethiopian households face, food insecurity and food price shocks are the most common ones. Demeke et.al (1995) pointed out that, despite many efforts, food insecurity is still a prominent feature of Ethiopia. Half of the food insecure population of the Sub Saharan Africa is found in Ethiopia, which is one of the seven food insecure country in Sub Sahara Africa. As pointed out above UNDP (2013) also reported, in human development index, Ethiopia ranked $173^{\text {rd }}$ out of 186 countries.

Nearly a quarter of the population in Ethiopia is malnourished where the largest proportion suffers from 
chronic hunger. Some assessments indicate that the probability of crop failure in certain parts of Ethiopia could reach 10 per cent (COLLIER and GUNNING, 1999: 76; FAO, 2006). This can be much worse where policies in attaining food security are underemphasized and the gap between per capita food production and consumption is induced by the slowdown of the agricultural production growth rates (FDRE, 2001).

According to CARE (2014), and World Bank (2014), report in all nine regions of Ethiopia, rural households were more likely to report food shortages, but the highest prevalence of perceived food shortages was found in Somali (25\% of urban, $31 \%$ of rural), Southern Nation Nationality People Regional (mainly rural at $37 \%$ ), Gambela (mainly rural at 35\%), and Amhara (mainly rural at 26\%).

The food insecurity situation in the Humbo woreda, Wolaita zone of Ethiopia shares similar features with that of the other regions (WVE, 2007). The problem of food insecurity has wide diversity and multiple dimensions, which ranges from the global to individual level. Previous studies have emphasized analysis at broader level. Nevertheless, variability, complexity and interrelated causes of household food insecurity and local responses during crisis require an analysis to move down to a household level. It is with regard to this that this study began with the primary objective of analyzing the determinants of household food insecurity and generate evidence for policy decisions where interventions are required to alleviate food insecurity. It also contributes to the food security literature within the context of the developing countries.

The overall objective of this study was to identify the determinants of food insecurity of smallholder farmers in Humbo Woreda. And the specific objectives was

$\checkmark$ To study the socio-economic characteristics of the food-secured and the food-in secured rural households;

$\checkmark \quad$ To analyze the major causes for food insecurity at household level in the area;

$\checkmark$ To assess the coping strategies of the farm households to overcome food insecurity.

\section{Research methods}

\subsection{Description of the study area}

Humbo is one of the woreda in the Southern Nations, Nationalities and Peoples' Region of Ethiopia-about 172 mi (or $276 \mathrm{~km}$ ) south of Addis Ababa, the country's capital place. Part of the Wolayita Zone located in the Great Rift Valley, Humbo is bordered on the southeast by Lake Abaya which separates it from the Oromia Region, on the south by the GamoGofa Zone, on the west by Offa, on the northwest by SodoZuria, on the northeast by DamotWeyde, and on the east by the Bilate River which separates it from the Sidama Zone. The administrative center of Humbo is Tebela. According to a 2004 report, Humbo had 25 kilometers of asphalt roads, 24 kilometers of all-weather roads and 51 kilometers of dry-weather roads, for an average road density of 118 kilometers per 1000 square kilometers.(http://www.tripmondo.com)

Based on the 2007 Census conducted by the CSA, this woreda has a total population of 125,441 , of whom 63,017 are men and 62,424 women; 6,247 or $4.98 \%$ of its population are urban dwellers. The majority of the inhabitants were Protestants, with $87.15 \%$ of the population reporting that belief, $7.87 \%$ practiced Ethiopian Orthodox Christianity, and 4.07\% were Catholic. The 1994 national census reported a total population for this woreda of 96,642 of whom 48,339 were men and 48,303 were women; 2,764 or $2.86 \%$ of its population were urban dwellers. The three largest ethnic groups reported in Humbo were the Welayta (96.33\%), the Amhara $(1.28 \%)$, and the Sidama $(0.86 \%)$; all other ethnic groups made up $1.53 \%$ of the population. Welayta is spoken as a first language by $96.8 \%, 1.5 \%$ Amharic, and $0.88 \%$ speak Sidamo; the remaining $0.82 \%$ spoke all other primary languages reported.(http://www.tripmondo.com)

\subsection{The Data collection and methodology}

\subsubsection{Data type, sources and method of data collection}

Data collection is the technique of gathering and measuring information on variables of interest, in an established systematic fashion that enables one to respond to stated research questions, test hypotheses, and evaluate outcomes (Dodge, 2003). Information pertaining to respondents, socio-economic characteristics and other related issues was obtained directly through the structured questionnaire interview, which was conducted at the household level. Secondary data was obtained from government offices and other relevant organizations. For this study both primary and secondary data was collected, of both qualitative and quantitative types, in order to address the objective of the study.

\subsubsection{Primary data}

Primary data are the data observed or collected directly from first-hand experience. In this study, the primary data collected included socio-economic characteristics of respondents.

\subsubsection{Secondary data}

Secondary data are the data that are collected by someone else, or for a purpose other than the present one. In this study secondary data such as past records on food insecurity was collected through reviewing literature from various sources such as journals, books, reports from Humbo Woreda agriculture and cooperative offices, and 
internet and research publications from libraries.

\subsubsection{Qualitative data}

Qualitative data are the data which describe items in terms of some quality or categorization. Qualitative data was involved in the study.

\subsubsection{Quantitative data}

Quantitative data are the data in which items are described in terms of quantity and in which a range of mathematical values are used without implying that a particular numerical value refers to a particular distinct category.

\subsection{Sample size and Method of Sampling Sampling Technique}

Three-stage sampling techniques were used to generate the required primary data. At the first stage, Humbo woreda was purposefully selected, as the problem of this study had been previously observed. In the second stage, six peasant associations were selected randomly from Humbo woreda. Finally, a probability proportional to sample size sampling procedure was employed to select 182 sample households randomly.

\subsection{Methods of Data Analysis}

Both qualitative and quantitative techniques were used to analyze the data. Qualitative data that was obtained by observation and focus group discussion structured and described the process in the field. Quantitative data was analyzed by using descriptive statistics. Descriptive statistics is one of the techniques used to summarize information or data collected from a sample. Such techniques as mean, standard deviation, frequency distribution, etc., were used to compare and contrast different categories of sample units - in this case, farm households with respect to the desired characteristics - so as to draw some important conclusions. Moreover, chi-square and t-test were applied to test for statistical significances.

\subsubsection{Econometric Method of analysis}

After the collection of qualitative and quantitative data from farmers was summarized, it was coded and entered into version 16 spreadsheets of the software program Statistical Package for Social Sciences (SPSS) for analysis of the probability of food insecurity. Regression models in which the regressed evokes a yes or no, or present or absent response, are known as dichotomous, or binary, dependent variable regression models. They are applicable in a wide variety of fields and are utilized extensively in survey or census-type data (Gujarati,1995). The dependent variable in this study was additionally a dummy variable, which gives a value of zero or one depending on whether or not the food insecure. However, the independent variables were of both continuous and categorical types. Food insecurity were expected to depend on different socio economic and other factors. The econometric model that was used to empirically identify the factors behind food insecurity was Logit Model. This model was selected because food insecurity, in which the dependent variable is binary, takes the value 0 and 1 for food secure and food insecure respectively. There are several methods to analyze the data involving binary outcomes. However, for this particular study, the logit model was chosen from among other similar models such as linear probability, probit and tobit models.

The linear probability model (LPM), which is expressed as a linear function of the explanatory variables, is usually simple. However, despite its computational simplicity, Linear Probability Model (LPM) is plagued by many problems. These include non-normality, heteroscedasticity of the error term, and possibility of the dependent variable lying outside the 0-1 range. If this situation occurs, it assumes that the mean value of the dependent variable is linearly related with the explanatory variable. That is, the marginal effect of the explanatory variable remains constant throughout, which seems patently unrealistic (Gujarati, 1995).

The logit and probit models would ensure that the estimated probabilities lie between the logical limit 0 and 1 (Pindyck and Runbinfeld, 1981). Because of this and other services, the logit and the probit models are the most frequently-used models when the dependent variable happens to be dichotomous (Liao, 1994; Maddala, 1989; Gujarati, 1995). Ignoring the minor distinctions between logit and probit models, Liao (1994), Gujarati (1995), Pindyck and Runbinfeld (1981)show that the probit and logit models are quite homogeneous, so they usually generate predicted probabilities that are almost identical. In the analysis of studies involving qualitative choices, usually a choice has to be made between logit and probit models. According to Amemiya (1981),the arithmetical similarity between logit and probit models makes the choice between them difficult. However, Maddala (1983) and Kmenta (1986) reported that many authors tend to accede in that the logistic and cumulative ordinary functions are very proximate in the midrange, but the logistic function has remotely heavier tails than the cumulative ordinary functions.

Pindyck and Rubinfeld (1981) and Gujarati (1988) illustrated that the logistic and probit formulations are quite equivalent, the main difference being that the former has remotely flatter tails; that is, the usual curve approaches the axis more rapidly than the logistic curve.

Aldrich and Nelson (1984) denoted that in practice these models yield estimated select probabilities that 
differ by less than 0.02. Liao (1994) shows that the logit model has the advantage that these predicted probabilities could be arrived at easily. In addition, he denoted that when there are many observations at the boundaries of the distribution, then the logit models preferred over the probit model. For statistical analysis, the logit model was employed due to the nature of the decision variable (whether smallholder farmers are food secure or food insecure). The logistic model considers the relationship among a binary dependent variable and a set of independent variables, ether binary or continuous. For such a dichotomous outcome, the logit model was determined to be the most suitable analysis tool for this study.

An extension of the probit model is the Tobit model. In tobit, which is an example of a general class of models known as censored regression models (additionally known as constrained dependent variable models), values of the regressed are not available for some observations, although values of the regressors are available for all the observations. Such models are usually estimated by the maximum likelihood methods (Gujarati, 1995).

Hosmer and Lemeshew (1989) indicated that the logistic distribution (logit) has the advantage over the others in the analysis of dichotomous outcome variables; it is very flexible and the most easily-used model from a mathematical perspective, given its simplicity of calculation. Its probability lies between 0 and 1 and results in a meaningful interpretation. Hence, the logistic model was chosen for this study. 1981):

The cumulative logistic probability model is econometrically defined as follows (Pindyek and Rubinfeld,

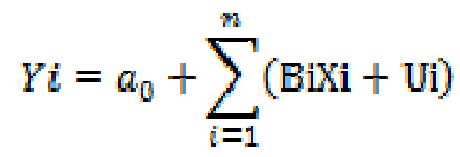

Where $\mathrm{Y} i=$ the dependent variable that means probability of food insecurity.

$\mathrm{X} i=$ Vector of explanatory Variables.

$\beta i=$ Vector of Unknown parameters.

$\mathrm{U} i=$ Disturbance or Error term, that represent all factors that affect the probability of food insecurity but those which are not taken in to account explicitly.

\subsubsection{Variables Specification}

1. Dependency ratio (Depratio): In a household where adults or productive age groups are higher than the non-productive age groups, the probability of the household to be in shortage of food would be less, provided that the area provides good working atmosphere and production potential. The reverse is also true in that the higher the number of the nonproductive age groups, individuals whose ages are less than 15 years and greater than 65 years, in relation to the number of productive age groups of individual that the household has, the higher the probability of the household to be food insecured. Leave alone the productive potential and other issues dependency ratio in the study area is substantially high. Most individuals share what the few productive age groups produce. Accordingly, households with large dependent individual are deemed to be food insecured. Therefore, it is expected for dependency ratio to be directly related with food insecurity.

2. Age( Age): It measures age of the household head in years. Rural households are mostly devoting their time to farming activities. As age of household increases, they can acquire more knowledge and experience and pre assume vulnerability and risk conditions of food insecurity, they become more risk averter and the chance of a household to become more food secure increase. Thus in this study, age of household head is hypothesized to affect food security status positively. This hypothesis is supported by findings of some researchers that age has positive relation with food security or negative relation with food insecurity status of households.

3. Education (Education): Education equips individuals with the necessary knowledge of how to make living. Literate individuals are very ambitious to get information and use it. As agriculture is a dynamic occupation the conservation practices and agricultural production technologies are always coming up with better knowledge. So if the household head is literate he/she will be very prone to accept extension services and soil and water conservation practices including any other income generating activities. Hence, in the study area different activities are undergoing and it is perceived that households who have had at least primary education or informal education are the ones more likely to participate than the others and their chance to be food secured will be higher. As a result it is expected that education to have negative impact on food insecurity.

4. Use of Irrigation (Irrigation): It is a dummy variable in the model taking value 1 if the household uses irrigation, 0 otherwise. Needless to mention in areas where agriculture is the prime mover of the livelihoods of the society moisture is very crucial. If the climatic condition in a given area is promising, then it would be better to be supplemented with irrigation so that increased production output could be attained. Irrigation is 
the key technology to boost the production of the households; many agencies are trying to upgrade the existing traditional irrigation technology. As a result, many households keep on improving their production. With this justification it is hypothesized that irrigation and food insecurity are negatively related also in the study area we get negative relationship.

5. Sex of household head (Sex): Dummy variable taking value 1 if the household head is male, 0 otherwise. In the study area, where the environment is debilitating smallholders, farmers are not working for a long time in a day like in the highland. As a result labor factor plays a great roll in such an area. Hence, male-headed households are in a better position to pull labor force than the female headed ones. Moreover, with regard to farming experience males are better than the female farmers. So sex of the household head is an important determinant of food insecurity in the study area. As a result it is expected that sex to have negative impact on food insecurity Therefore, it is hypothesized that male-headed households are less likely to be food insecure.

6. Family Size (Famsize): It is believed that the larger the family members, the more the labor force available for production purpose. The study here shows that the more the families size the lower the food insecurity, because, large family size imply self sufficiency in terms of food consumption that's way large households consume more than do small households. Therefore, family size was negatively related to food insecurity but not significantly.

7. Use of Chemical Fertilizer (Fertilizer): It is represented by a dummy variable taking value 1, if fertilizer used; 0 , otherwise. Fertilizer use has often been perceived as improving yield per unit area. Therefore, it was hypothesized that households using fertilizer are expected to have better food security than the non-users. Hence, it is expected that the availability of fertilizer is negatively associated with household food insecurity status.

8. Other sources of income (Otherincom): This represents the amount of off-farm income (in cash or in kind) the farmer or any of the household members earned in the year. Since smallholder farmers have inadequate farm income they often look for external source of income to purchase food and farm inputs. The success of households and their members in managing food insecurity is largely determined by their ability to get access to off farm job opportunities in the study area. In this regard, households engaged in off-farm activities are better endowed with additional income to purchase food. Hence, it is expected that the availability of off-farm income is positively associated with household food security status.

9. Farm credit use (Credit): It is a dummy variable in the model taking value 1, if farmers got farm credit and 0 otherwise. Credit is an important source of earning future income. Those households who received farm credit have possibility to invest in farming activities, which is important component in small farm development programs. In the study area, farm households who have easy access to credit at times of peak season of cultivation avail it and increase their production. Hence, it was expected that credit in general have a negative impact on food insecurity status.

10. Food Aid(Foodaid): This variable stands for relief food, food-for-work and food obtained through employment generation schemes. Since Humbo is one of the food-insecure districts of SNNP. Distribution of more food aid implies that there are more food-insecure households in the area. Hence, it is hypothesized that there is a negative relationship between food insecurity status of the household and food aid because food aid have its own role for micro level employment creation and so on.

11. Livestock Owned(Livestock): Livestock is one of the important resources of farmers, which is used as one of the few sources of household income. Moreover, it is often used as a strategic resource, in that it plays a double role in the household economy. One is that it can be kept as a hedge against food insecurity during bad years. During normal years, it is used as an alternative income source of the household. During crises it is the first asset at the disposal of the farmer that can bring cash money to purchase food as a coping mechanism. Livestock is an accumulated wealth, source of income in case of emergency and a guaranty against future hardship. Therefore, livestock have negative relationship with food insecurity.

12. Land Size(Landsize): this variable stands for total land size owned by the household per adult equivalent. Land is one of the key assets farmers own to earn their livening; hence, it is also one of the major sources of income for the household. So it is hypothesized to have a negative relationship with the dependent variable, meaning that farmers who have relatively large land holding are likely to be less food insecure or more food secure than those having smallholdings.

\subsection{Results of the Logit model}

In this section, selected explanatory variables were used to estimate the logistic regression model to analyze the determinants of households' food insecurity. A logit model was fit to estimate the effects of the hypothesized explanatory variables on the probabilities of food insecurity. Finally, a set of 12 explanatory variables were included in the logistic analysis. These variables were selected on the basis of theoretical explanations, personal observations and the results of the survey studies. To determine the best subset of explanatory variables that are 
good predictors of the dependent variable, the logistic regressions were estimated using the Statistical Software Program (SPSS) Version 16. The definition and unit of measurement of the variables used in the model are presented in Table below.

Variables in the Equation

\begin{tabular}{|cl|c|c|c|c|c|c|}
\hline & & B & S.E. & Wald & df & Sig. & Odd ratio \\
\hline Step $1^{\text {a }}$ & Age & -.304 & .269 & 1.279 & 1 & .258 & .738 \\
& Sex & .587 & .541 & 1.181 & 1 & .277 & 1.799 \\
& Education & .270 & .270 & 1.001 & 1 & .317 & 1.310 \\
& Famsize & -.332 & .356 & .871 & 1 & .351 & .717 \\
Depratio & -.409 & .451 & .823 & 1 & .364 & .664 \\
Fertilizer & -.996 & .569 & 3.064 & 1 & $.080^{* * *}$ & .369 \\
Otherincom & 1.669 & 1.132 & 2.174 & 1 & .140 & 5.306 \\
Irrigation & -1.919 & .579 & 10.986 & 1 & $.001 *$ & 6.811 \\
Landsize & -.895 & .517 & 2.996 & 1 & $.083 * * *$ & .409 \\
Livestock & -3.421 & 1.166 & 8.606 & 1 & $.003 *$ & .033 \\
Foodaid & -1.403 & .482 & 8.474 & 1 & $.004 *$ & .246 \\
Credit & -1.507 & .554 & 7.410 & 1 & $.006 *$ & .222 \\
Constant & 9.171 & 2.258 & 16.490 & 1 & .000 & $9.617 \mathrm{E} 3$ \\
\hline
\end{tabular}

a. Variable(s) entered on step 1: Age, Sex, Eduaction, Famsize, Depratio, Fertilizer, Otherincom, Irrigation, Landsize, Livestock, Foodaid, Credit.

-2 Log likelihood $=143.810^{\mathrm{a}}$

$\chi 2(12)=45.317$

Correctly predicted overall sample $=81.3 \%$

correctly predicted food secured $=30.8$

Correctly predicted food insecure $=95.1 \%$

Cox \& Snell R Square $=0.220$

Sample size $=182$

Note: $*, * * \& * * *=$ significant at $1 \%, 5 \% \& 10 \%$ respectively

Source: model output, Dec. 2018

1. Use of Chemical Fertilizer (Fertilizer): Use of Chemical Fertilizer has come out to be significant and negative influence on the food insecurity status of the household. The negative sign is an indicator of its influence in affecting food insecurity status. The possible explanation is that those who have no access to fertilizer are more likely to be food insecure and those farmers who have access to fertilizer use are more likely to be food secure. The odds ratio of 0.369 for this variable indicates that, if other factors are kept constant, the odds ratio in favor of being food insecure decreases by 0.369 as a farmer gets access to the use of fertilizer increased by one.

2. Use of irrigation (Irrigation): Use of irrigation shows a significant $(\mathrm{p}<0.05)$ and negative relationship with food insecurity in the study area. The negative relationship indicates that using irrigation reduces the risk of food insecurity among the sample households. By definition odds ratio means the ratio of the probability of occurrence to the probability of none occurrence. In this case it is the ratio of the probability of being food insecure to the probability of being not food insecure. Here, odds ratio with respect to this variable came out to be 6.811 . This means the probability of food insecurity decrease by 6.811 when households are becoming users of irrigation.

3. Land Size (Landsize): This variable has a significant differentiating power in respect of household food insecurity status. It is one of the powerful variables, which has a negative relationship with the food insecurity status of the household. This means that those households, which have larger land size, are better-off (food-secure) than those with smaller land size, which are worse off (food-insecure). This result suggests that food insecurity is more severe among those households with little land holdings. The odd ratio indicates that, as the households with small land size, where all other factors remain constant, his/her probability of food insecure increased by 0.409 . This result is in line with the findings of Getachew (1995) and it is in agreement with our hypothesis too.

4. Livestock Owned (Livestock): Livestock are important source of income, food and draft power for crop 
cultivation. Livestock size is negatively and significantly associated with the probability of being food insecure in the study area. This indicates that households with more livestock produce more milk, milk products and meat for direct consumption and owners could be less food insecure. Besides, this enables the farm households to have better chance to earn more income from livestock production which enables them by increasing purchasing power of food during food shortage and could invest in purchasing of farm inputs that increase food production, and able in ensuring household food security. Hence, this empirical finding support that larger livestock holding is important source of income in explaining the probability of being food secure in the Humbo District. The result indicates that, other things held constant, the odds ratio in favor of being food insecure decreases by 0.033 as the total livestock holding increase by one. Earlier studies also reveal that livestock is one factor that affect food insecurity. Alemu (2000).

5. Food Aid (Foodaid): Food aid has a significant role to play in mitigating food insecurity. If timely, it can not only save lives, particularly those of women and children, but also help food-insecure households to avoid sale of household assets or consumption of seeds. If the distribution of food aid is carefully planned, much of socio-economic distress associated with extreme food-insecurity can be avoided. The study shows that there is significant (less than $1 \%$ ) mean difference between food-secure and food-insecure households regarding to food aid. Moreover, the results of the model support this and it has a negative relationship with the household food insecurity status. This means that food aid is targeted to the food-insecure households. The results suggested that, other things held constant, the odds ratio in favor of being food insecure decreases by 0.246 as food aid increase by one.

6. Farm Credit Use (Credit): Credit is important source of investment on activities that generate income for farm households. The households can purchase agricultural inputs (improved seed, fertilizer, etc.) and livestock for resale after fattening. In Humbo District, farm households who have access to credit could increase their production to escape food shortage. The logit model analysis revealed that credit has a significant negative association with food insecurity status. This is in agreement with the prior expectations about the impact of the differential access to credit service. This is because farm households who have the opportunity of accessing farm credit would build their capacity to produce more through purchasing of agricultural inputs. The households with more access to farm credit have possibility to reduce the probability of being vulnerable to food insecurity. From the study we get, other things remain constant the odds ratio in favor of food insecurity decreases by a factor of 0.222 as farm households get access to farm credit. This result agrees with the study carried out by Awoke (1995).

\section{CONCLUSION AND RECOMMENDATION}

\subsection{CONCLUSION}

This study was conducted in Wolaita zone of SNNP, where food insecurity is becoming virtually a continuous concern of most households. Food insecurity is now a crucial problem in Humbo district. Most of the farming households in the district have difficulties to cope with the situation even during normal seasons. Drought induced food insecurity has been a recurrent phenomenon exacerbating the vulnerability of the resource poor farming households in the district. Because of this, the objectives of the study were to identify the determinants of food insecurity and estimation of the food insecurity gap and severity of food insecurity. The socio-economic characteristics of both the food secured and insecure households, and the livelihood strategies of the rural households in the study area were also taken care of. To accomplish these objectives Three-stage sampling techniques has been used to identify the required sample. The primary data were collected from 182 respondents. Accordingly, the respondents were divided into food secure and food insecure households. Based upon their proportion, 39 food secure and 143 food insecure were taken for the study. Quantitative and qualitative data were collected using personal interviews, direct observations, etc. Logit model was used for analysis. According to the logit model results among 12 variables used in the model, 6 variables were statistically significant with less than $10 \%, 5 \%$ and $1 \%$ of the probability level. Those variables (Use of Chemical Fertilizer, Use of irrigation, Land Size, Livestock Size, Food Aid, and Farm Credit Use.) had a statistically significant impact at a different significance level on the probability of being a food insecure. However, the other 7 explanatory variables namely age, sex, education level, family size, dependency ratio, and other sources of income were found to have no significant influence on the probability of food insecurity.

\subsection{Recommendation}

This study presented important information, justification and findings concerning to determinants of food insecurity status of Humbo woreda smallholder farmers, were indicated in this paper. Based on the main findings of the study and literature reviewed the following points are made.

The result of econometric analysis revealed that households with small livestock holdings are more likely to be food insecure or with large livestock holdings are more likely to be food secure. Livestock is indicator of 
wealth that it provides additional farm income for farmers that help in purchasing food grain during the period of shortage of food. It also provides food and draft power that directly contributes to the betterment of food security status of the area. However, the livestock sector is constrained by several problems. Therefore it is imperative that development strategy should able to give due attention for livestock sector in improving livestock breeds, veterinary services, forage development, marketing and overall management of livestock production that aimed at improving rural household welfare in general and food security status of Hunbo woreda farmers.

Access to credit can create an opportunity to be involved in economic activity that generates revenue to households. Recently established small and micro business agency in the region has started activity of organizing and training of every business community who are interested. Provision of startup capital in the form of loan is effected through Omo micro finance institution. Development partners operating in the study area should implement provision of credit to eligible households using targeting criterion that reflects actual characteristics of food insecure households. The other pressing issue related to provision of credit is the requirement of collateral and group lending procedure, which discourages so many households. People are afraid of holding accountability for others so individual lending should be considered as another option and collateral requirement should be avoided if there is a need to lift food insecure households from their current situation. Borrowers should be encouraged to save or contribute as matching fund to reach the limited resources over large number of needy people.

Sustainable food security intervention must not exclude the improvement of production and productivity of agricultural sector through use of irrigation. As the findings of this study assured, irrigation and food insecurity are negatively and significantly related in the study area. Therefore, development strategies, programmes, or any intervention related with food security through agricultural production should not neglect the paramount importance of irrigation. Hence, the already launched irrigation development programmes should be further strengthened. However, it should be integrated with proper management of water use and input supplies. Therefore, farmers who have irrigable farmland should be encouraged to use inputs such as, improved seed, and pesticides through effective extension services and credit facilities.

Productive resources especially land is very limiting and highly binding resource in the study area. And hence, even if the model result showed land size and food insecurity have inverse relationship, tackling the problem of food insecurity through increasing farm size would not bring any sustainable improvement. So a medium and longer-term food insecurity strategy through increased food production must be introduced. In a medium or shorter term, distribution and allocation of cultivable land, which was not under cultivation, there by increasing output should be made. This would give short period relief from the problem, otherwise the amount of return from such a strategy would not be by any means sufficient and sustainable to up-root the problem from the present setting. As a result, strong effort should be made to improve the production and productivity in the agricultural sector in the longer term. The possible measures that can be undertaken to achieve this strategy include crop diversity, runoff and flood harvesting, timely and low cost supply of inputs like fertilizer, improved seed, agrochemicals, further development of micro-irrigation.

\section{Reference}

(AFC 2017)Africa Food Crisis 2017: Work Report 3 REPORTfrom Hong Kong Red Cross Published on 12 Jul 2017

Amelu A. (2000) Farmers' Perceptions of Land Degradation and Determinants of Household Food Security Status in Dera woreda Amhara region, Ethiopia

Awoke B. (1995) determinants of household food security the case of Arsi zone of oromia region, Ethiopia

CARE (2014), "Achieving food and nutrition security in Ethiopia". Finding from the CARE Learning Tour to Ethiopia, January 19-24, 2014, CARE, Washington, DC. pp: 1-15.

COLLIER, P. and J.W. GUNNING (1999): Explaining African Economic Performance. In:Journal of Economic Literature 37 (1): 64-111.

Demeke, M., W. Amha, S. Ehui and T. Zegeye (eds) (1995) 'Food security, Nutrition, and poverty Alleviation in Ethiopia: Problems and Prospects', Proceedings of the Inaugural and First 55 Annual Conference of the Agricultural Economics Society of Ethiopia, Addis Ababa, Ethiopia(8-9 June).

Dodge, Y. (2003). The oxford dictionary of statistical terms. Oxford University Press.

FAO (2010): State of food insecurity in the World: Eradicating world hunger, taking stock ten years the World Food Summit. Rome, Italy.

FDRE (Federal Democratic Republic of Ethiopia) (2001): Food Security Strategy. An update.Addis Ababa, Ethiopia: 8-22.

Food and Agriculture Organization (FAO).2010.TheStateofFood Insecurity in the World. Rome, Italy

Getachew Direba,1995; Economy at the crossroads: Famine and Food Security in Rural Ethiopia. Printed by commercial Printing Enterprise, Addis Ababa, Ethiopia.

Greenbaum, S.I., \& Thakor, A.V. (1995). Contemporary financial intermediation. Forth Worth, Texas: Dryden 
Press.

Gujarati, D.N. (1988). Basic econometrics 2nd edition. McGraw-Hill Book Company, New York, U.S.A.

Gujarati, D.N. (1995). Basic econometrics 3rd edition. McGraw-Hill, New York, U.S.A.

Gujarati, D.N. (2003). Basic econometrics 4th edition. McGraw-Hill, New York, U.S.A.

Hosmer, D.W. \& Lemeshew, S. (1989). Applied logistic regression. A Wiley-Inter-science publication. New York, U.S.A.

(https://en.wikipedia.org/wiki/Humbo)

(http://www.tripmondo.com/ethiopia/southern-nations-nationalities-and-people-s-region/humbo/)

Kmenta, J. (1986). Elements of econometrics 2nd edition. Macmillan Pub. Co. New York, U.S.A.

Maddala, G.S. (1983). Limited dependent and qualitative variables in econometrics. Cambridge university press. New York, U.S.A.

Maddala, G.S. (1989). Limited dependent and qualitative variable in econometrics. Cambridge University Press. New York, U.S.A.

MoFED(2013) 'Development and Poverty in Ethiopia'. Addis Ababa, Ethiopia: Ministry of Finance and Economic Development, Federal Democratic Repuplic of Ethiopia.

Pindyck,R.S. and Rubinfeld, Daniel L. (1981). Econometric models and economic forecasts 2 nd edition. McGraw-Hill Book Company. New York, U.S.A.

UNDP (2013) 'Summary of Human Development Report 2013- The Rise of the South: Human Progress in a Diverse World' Human Development Report, USA: United Nations Development Programme (UNDP).

UNFPA. (2011). Human development report, 4, 234 - 235. New York, USA.

World Bank (2014), "World Bank Open Data". Washington, DC

WVE (World Vision Ethiopia) (2007): Five years Design Document (2007-2011). World Vision Ethiopia, Addis Ababa Program Office, Ada Berga Area Development Program, Inchini. 